\title{
Using remotely sensed and climate data to predict the current and potential future geographic distribution of a bird at multiple scales: the case of Agelastes meleagrides, a western African forest endemic
}

\author{
Benedictus Freeman ${ }^{1 *} \mathbb{C}$, Daniel Jiménez-García², Benjamin Barca ${ }^{3}$ and Matthew Grainger ${ }^{4}$
}

\begin{abstract}
Background: Understanding geographic distributions of species is a crucial step in spatial planning for biodiversity conservation, particularly as regards changes in response to global climate change. This information is especially important for species of global conservation concern that are susceptible to the effects of habitat loss and climate change. In this study, we used ecological niche modeling to assess the current and future geographic distributional potential of White-breasted Guineafowl (Agelastes meleagrides) (Vulnerable) across West Africa.

Methods: We used primary occurrence data obtained from the Global Biodiversity Information Facility and national parks in Liberia and Sierra Leone, and two independent environmental datasets (Moderate Resolution Imaging Spectroradiometer normalized difference vegetation index at $250 \mathrm{~m}$ spatial resolution, and Worldclim climate data at $2.5^{\prime}$ spatial resolution for two representative concentration pathway emissions scenarios and 27 general circulation models for 2050) to build ecological niche models in Maxent.

Results: From the projections, White-breasted Guineafowl showed a broader potential distribution across the region compared to the current IUCN range estimate for the species. Suitable areas were concentrated in the Gola rainforests in northwestern Liberia and southeastern Sierra Leone, the Tai-Sapo corridor in southeastern Liberia and southwestern Côte d'Ivoire, and the Nimba Mountains in northern Liberia, southeastern Guinea, and northwestern Côte d'Ivoire. Future climate-driven projections anticipated minimal range shifts in response to climate change.

Conclusions: By combining remotely sensed data and climatic data, our results suggest that forest cover, rather than climate is the major driver of the species' current distribution. Thus, conservation efforts should prioritize forest protection and mitigation of other anthropogenic threats (e.g. hunting pressure) affecting the species.
\end{abstract}

Keywords: Climate change, Conservation, Conservation planning, Ecological niche modeling, Species distribution, Upper Guinea Forest, White-breasted Guineafowl

\footnotetext{
*Correspondence: benedictusfreeman@gmail.com

${ }^{1}$ Biodiversity Institute, University of Kansas, Lawrence, KS 66045, USA

Full list of author information is available at the end of the article
}

(c) The Author(s) 2019. This article is distributed under the terms of the Creative Commons Attribution 4.0 International License (http://creativecommons.org/licenses/by/4.0/), which permits unrestricted use, distribution, and reproduction in any medium, provided you give appropriate credit to the original author(s) and the source, provide a link to the Creative Commons license, and indicate if changes were made. The Creative Commons Public Domain Dedication waiver (http://creativecommons.org/ publicdomain/zero/1.0/) applies to the data made available in this article, unless otherwise stated. 


\section{Background}

West Africa is recognized as a global biodiversity hotspot, yet the ecology, distributions, and population numbers of most of its biota remain largely unknown (Mittermeier et al. 1998; Myers et al. 2000), which makes it challenging to optimize conservation of threatened species in the region. The region also ranks among the most deforested places on Earth, and is considered as highly susceptible to impacts of global climate change (Stattersfield et al. 1998; Myers et al. 2000; Malcolm et al. 2006; Janes and Hartley 2010; Díaz et al. 2018; IPBES 2018). As such, understanding likely relative impacts of these changes on geographic distributions of the region's biota is important for conservation planning and decision-making.

A research approach used to address such questions is ecological niche modeling, which integrates known occurrences of species and environmental variables (e.g. temperature, precipitation) to characterize potential future geographic distributions of species in response to global climate change (Pearson and Dawson 2003; Peterson et al. 2011). Ecological niche models are useful tools in predicting or identifying priority areas for research and conservation of species and particularly for poorly known species (Pearson et al. 2007; Guisan et al. 2013).

In this study, we used ecological niche modeling to assess the distributional status of a Vulnerable Forest Endemic bird species, the White-breasted Guineafowl (Agelastes meleagrides) across West Africa. White-breasted Guineafowl belongs to the family Numidae and order Galliformes. Galliformes are thought to be highly susceptible to climate change owing to their relative inability to disperse over large distances and their consequently high site-fidelity (WPA-IUCN 2009). Habitat loss and climate change both have drastic effects on the distributions and populations of birds (Şekercioğlu et al. 2012; Stephens et al. 2016).

Previous studies attempting to understand the ecology and distribution of White-breasted Guineafowl have been patchy (Francis et al. 1992; Klop et al. 2010; Waltert et al. 2010; Freeman et al. 2019a, b), perhaps leading to an underestimation of the range of the species. For example, in 1986, one of the first surveys to be conducted in what was then known as the Gola Forest Reserves in Sierra Leone confirmed its presence, with six encounters across both primary and secondary forest habitat (Davies 1987), the first live records of the species in Sierra Leone, a country that by then had already seen most of its lowland forest cleared to make way for farming and plantations. Today, the Gola Rainforest National Park (GRNP) in Sierra Leone is believed to harbor one of the largest and westernmost populations of the species (Allport 1991; Dowsett-Lemaire and Dowsett 2007; Klop et al. 2010), and the species has been used as an indicator of a healthy habitat and low hunting pressure (Fuller and Garson 2000). This species is endemic to the Upper Guinea Forest biome, occurring in remnant forest patches in Sierra Leone, Liberia, Côte d'Ivoire, and Ghana (IUCN 2018). It is considered to be tolerant of some disturbance, occurring in previously logged sites at high densities (Waltert et al. 2010). The species is nonetheless threatened by habitat loss and heavy poaching (snares and shooting) across most of its range (Fuller and Garson 2000). Its population is estimated at between 85,000 and 115,000 individuals, and the species is considered Vulnerable on the IUCN Red List in view of recent rapid population declines. Like most West African species, the ecology and distribution of White-breasted Guineafowl remain poorly known (Francis et al. 1992; Waltert et al. 2010). For example, the current IUCN estimated range map of the species does not include key areas in Liberia where the species has been recorded (e.g. Sapo National Park; Fig. 1). With such gaps in the current knowledge of the ecology and distribution of the species, success of interventions to assure the species' conservation could be limited.

Here, we aimed to (1) estimate the current geographic distribution of White-breasted Guineafowl, (2) assess impacts of global climate change on the current and potential future geographic distribution of the species, and (3) identify priority areas for research and conservation of the species.

\section{Methods \\ Input data}

This study was conducted across the Upper Guinea lowland rainforest of West Africa, which is one of two major forest blocks in West and Central Africa, a global biodiversity hotspot, and a BirdLife International-designated Endemic Bird Area. Primary occurrence data for Whitebreasted Guineafowl were obtained from two sources: the Global Biodiversity Information Facility (GBIF 2017) and surveys in two national parks in Liberia and Sierra Leone (Sapo National Park in Liberia and Gola Rainforest National Park in Sierra Leone). The data obtained were error-checked, for example, for precision in GPS coordinates and wrong arrangement of longitude or latitude, and improved where necessary to meet appropriate standards for ecological niche modeling as explained below. To this end, for GBIF data, we split the dataset into georeferenced and non-georeferenced portions. Georeferenced data were checked for errors and data consistency as regards geographic coordinates (Chapman 2005). Where possible, errors were fixed; otherwise, erroneous data points were removed from the datasets. Nongeoreferenced data that had detailed both datasets were rarefied spatially to remove duplicate points, using SDM Toolbox v2.2b in ArcGIS v10.4.1 (Brown 2014). We split 


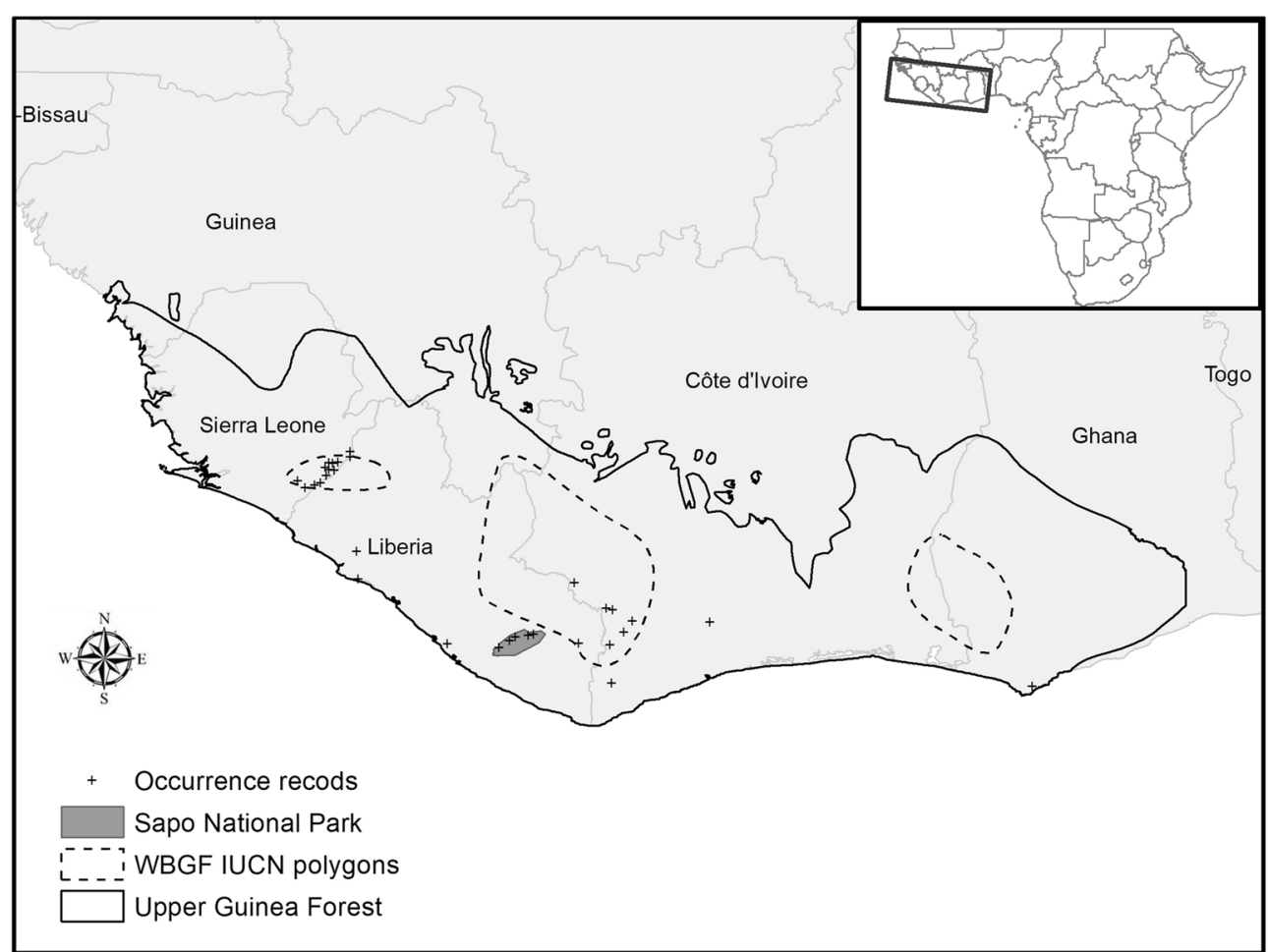

Fig. 1 Map of West Africa showing the boundaries of Upper Guinea Forest, the current IUCN view of range limits of White-breasted Guineafowl, and Sapo National outside the IUCN range estimate of the species in southeastern Liberia

the two occurrence datasets into two portions each: 70\% for model calibration and 30\% for evaluation.

Next, we acquired two independent environmental datasets, remotely sensed data and climatic data, for building ecological niche models. For climatic data, we acquired 15 climatic variables at $2.5^{\prime}(\sim 5 \mathrm{~km})$ spatial resolution, characterizing temperature and precipitation and their seasonality for present-day climatic conditions (Hijmans et al. 2005). To characterize future climate conditions, we used data for two IPCC representative concentration pathway (RCP 4.5, 8.5) emissions scenarios and 27 general circulation models (GCMs), all for one future time period (2050; Hijmans et al. 2005; Additional file 1: Table S1). The RCPs summarize low and high emissions scenarios as regards greenhouse gases, and the GCMs represent independent simulations of global climate processes and thus allow understanding of uncertainty as regards future climate patterns. For remotely sensed data, we obtained Moderate Resolution Imaging Spectroradiometer (MODIS 2017) normalized difference vegetation index (NDVI) data layers at $250 \mathrm{~m}$ spatial resolution from 2012 to 2016 for the region. The MODIS data consist of gridded vegetation index maps that depict temporal and spatial variations in the earth's vegetation activity (Didan et al. 2015). These vegetation indices are derived on 16-day and monthly intervals and provide consistent, spatial and temporal time series comparisons of global vegetation conditions that can be used to monitor the Earth's terrestrial photosynthetic vegetation activity in support of phenologic, change detection, and biophysical interpretations (Huete et al. 1999; Didan et al. 2015). Environmental datasets were processed as explained below.

First, we delineated our calibration area $(M)$, which corresponds to the region accessible to the species over relevant time periods (Barveet et al. 2011). Defining the correct boundary and size of this area is crucial to obtaining good predictions (Barve et al. 2011). We delineated two $M$ areas: one for the fine-scale occurrence data from national parks and the remotely sensed environmental data, and the second for the coarse-scale data from the broader set of primary occurrence records and the climatic data. To determine a calibration area for the fine-scale datasets, we buffered the well-sampled Gola Rainforest National Park in Sierra Leone by $100 \mathrm{~km}$ (Fig. 2); and for coarse-scale datasets, we used ecoregions of West Africa (Olson and Dinerstein 2002), buffering the ecoregion with the highest concentration of occurrence points by the nearest ecoregion on each side (Peterson et al. 2011). All environmental variables were masked 


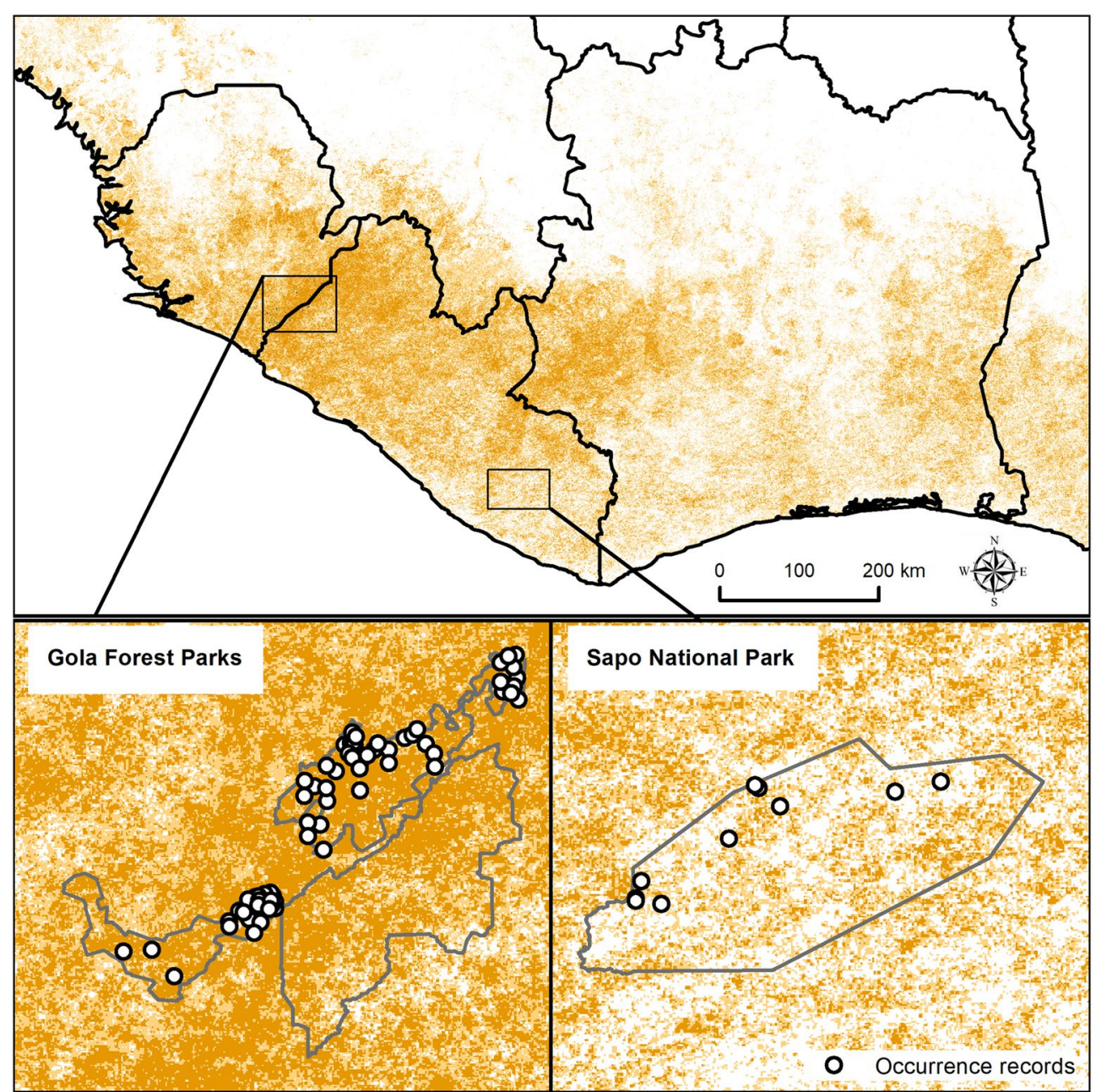

Fig. 2 Current geographic distribution of White-breasted Guineafowl across West Africa as predicted by models based on remotely-sensed data using two threshold values. Light red areas are at 5\% threshold, whereas dark red areas are at 20\% threshold

to the corresponding extent of $M$ for each dataset using the "extract by mask" function in ArcGIS version 10.5.1 (ESRI 2017). Subsequently, to determine subsets of important environmental variables with which to calibrate our models for the climatic dataset, we eliminated one variable from each pair of the 15 climatic variables presenting Pearson correlation coefficients above 0.8. With this reduced set, we implemented a "leave-one-out" jackknife approach in Maxent using the environmental variable and all occurrence points for the species (Phillips et al. 2006; Pearson et al. 2007; Shcheglovitova and Anderson 2013). Based on the test gain distributions in these analyses, we selected three subsets of uncorrelated variables for further testing.

For the MODIS dataset, in which vegetation index data from successive time periods can be highly intercorrelated, we applied three principal components analysis approaches: T-mode, S-mode, and Fourier to reduce colinerity or spatial and temporal autocorrelation (Martins et al. 2012; Zhang et al. 2012; Gocic and Trajkovic 2014; Eastman 2015). In T-mode, each image in the series is considered to be an independent variable in the analysis, components are images and the loadings are graphs (Zhang et al. 2012). In contrast, in S-mode, each pixel is considered as an independent sample in space and time; components are graphs and the loadings are images (Martins et al. 2012; Gocic and Trajkovic 2014). Fourier approaches use time series transposed into a set of Fourier components (amplitudes and phases) and apply principal components analysis (Manjunath Aradhya et al. 2010; Sobrino and Julien 2013). Following the analysis, we selected three subsets each of T-mode, S-mode, and Fourier variables for modeling. Following the data processing for both occurrence and environmental datasets, we left with 67 occurrence records for MODIS data and 31 occurrence records for climatic data. 


\section{Ecological niche modeling}

We used the Maxent algorithm to estimate the ecological niche of our target species (Phillips et al. 2006). To calibrate models and choose optimal parameter values, for climatic variables (coarse-scale data), we assessed 29 combinations of Maxent feature classes (all possible combinations of linear, quadratic, product, threshold, and hinge features) as they interacted with 17 regularization multiplier values $(0.1,0.2,0.3 \ldots 1,2,4,5,6,8$, and 10$)$. For MODIS variables, we assessed a simpler set of five combinations of Maxent feature classes (linear, quadratic, product, threshold, and hinge) as they interacted with nine regularization multiplier values $(0.1,0.3,0.5,0.7,1$, $3,5,7$, and 10) to speed up the processing time, given the high spatial resolution of this dataset. For both fine-scale and coarse-scale analyses, we split the occurrence data into two portions: $70 \%$ for model calibration and $30 \%$ for evaluation. We evaluated candidate models and selected best models using the Akaike information criterion corrected (AICc) for small sample sizes to evaluate model complexity (Hurvich and Tsai 1989), performed significance tests using partial ROC (Peterson et al. 2008), and evaluated performance using a 5\% training presence threshold to evaluate omission (Peterson et al. 2011).

Finally, to generate binary maps of the present and future time periods, we transferred the final ("best") models to the present and future (climatic data only). We applied a 5\% training omission threshold. To assess the vulnerability of White-breasted Guineafowl to global climate change, we combined medians of the present and 27 future projections for each RCP to create a visualization that shows the potential for range expansion, range retraction, and range stability (Campbell et al. 2015). All analyses were performed in ArcGIS version 10.5.1 (ESRI 2017) and the "kuenm" R Package (Cobos et al. 2019).

\section{Results}

In all, 405 candidate models were calibrated for Whitebreasted Guineafowl using the MODIS dataset. All 405 candidate models performed significantly better than random expectations $(p<0.001) ; 123$ models met our $5 \%$ omission rate threshold; and five models were within two units of the minimum AICc scores. Of the 123 models with low omission rates, 75 were candidate models built with T-mode variables (including the five models within two units of the minimum AICc), whereas only 7 and 41 models were for Fourier and S-mode respectively. Of the five candidate T-mode models within two units of the minimum AICc and low omission rates, only one had zero omission rate. This model was selected as the best model and projected across the full extent of our region of interest (Fig. 2; Additional file 1: Table S2). From the model projections, White-breasted Guineafowl showed a broader distribution across its range compared to IUCN's highly fragmented estimated range for the species (Figs. 1 and 2). Suitable areas in model outputs were concentrated in the Gola rainforest complex in northwestern Liberia and southeastern Sierra Leone; the Tai-Sapo complex in southeastern Liberia and southwestern Cote d'Ivoire; and the Nimba Mountains in northern Liberia, southeastern Guinea, and northwestern Cote d'Ivoire (Fig. 2). Our projections also showed a significant extent of suitable habitat in southwestern Ghana and southeastern Cote d'Ivoire (Figs. 1, 2).

For climate variables, using parameters reflecting 17 values of regularization multiplier values as they interacted with 29 combinations of feature classes and three sets of environmental variables, we built a total of 1479 candidate models. All candidate models performed significantly better than random $(p<0.001) ; 236$ models met our $5 \%$ omission rate threshold and minimum AICc criteria, whereas one met our triple threshold for model complexity, performance, and significance (Additional file 2). The present climate-based potential geographic distribution of the species based on our final model showed a range almost entirely restricted to Liberia, with only a few patches of suitable conditions in southwestern Côte d'Ivoire, southwestern Ghana, and southeastern and northwestern Sierra Leone (Fig. 3). Future projections showed high stability in the species' range across Liberia, and minimal suggestion of range shift or loss in response to climate change (Fig. 3). We found only moderate tendency for range expansion in response to climate change at the northwestern (Sierra Leone) and southeastern (Côte d'Ivoire and Ghana) extremes of the range of the species (Figs. 3, 4). The results of the two RCPs were closely similar (Fig. 3).

\section{Discussion}

This study lays out the first detailed model-based projections of the geographic distribution of White-breasted Guineafowl across the Upper Guinea lowland rainforest region, providing a baseline for regional-to-local-level conservation planning and decision-making. Our results confirmed that GRNP and its sister reserve Gola Forest National Park (GFNP) in Liberia hold broad suitable areas for White-breasted Guineafowl, emphasizing the importance of these sites in the conservation of the westernmost range of the species. The good news here is that these two areas are designated protected areas in both countries. The decree of GFNP by the Liberian government in 2016 created a transboundary landscape or corridor between Liberia and Sierra Leone to increase the dispersal potential of species in general, including, the White-breasted Guineafowl within a protected environment across the Gola forest landscape. 


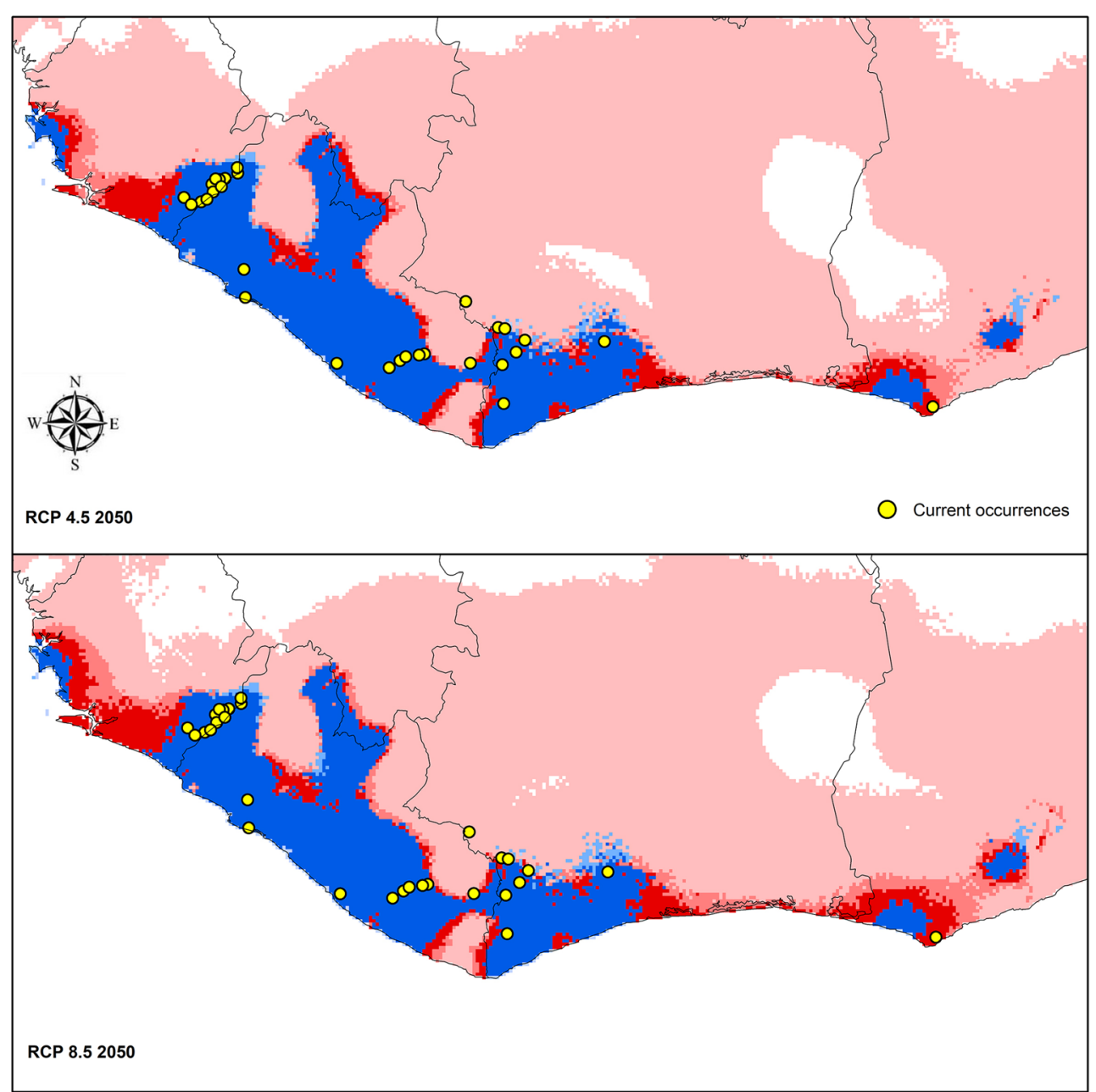

Fig. 3 Current and potential future distributions of White-breasted Guineafowl for two emissions scenarios (top, RCP 4.5; bottom, RCP 8.5) in 2050. Dark blue: areas predicted to be suitable in present and in the future; medium light blue: areas predicted to be suitable in present but with reduced probability of presence in the future; light blue: areas predicted to be suitable in present and completely unsuitable in the future; dark red: areas unsuitable in the present, but with a strong chance of suitability in the future; medium red: areas predicted to be unsuitable in present but with a moderate chance of suitability in the future; light red: areas predicted to be unsuitable in present but have slight chance of suitability in the future, and white: areas unsuitable in both present and the future

Additionally, we acknowledge current efforts to create a network of protected areas across the region to increase transboundary landscape connectivity in Liberia, Sierra Leone, Guinea, and Cote d'Ivoire (e.g. GRNP Sierra Leone/GFNP Liberia; Ziama Guinea/Wonogizi Liberia; Tai Côte d'Ivoire/Sapo-Grebo Liberia) that will optimize overall biodiversity conservation across the region. However, for threatened species, such efforts need to be extended to fragmented isolated populations/habitats outside these targeted landscapes (Freeman et al. 2019a, b). For instance, the easternmost population of Whitebreasted Guineafowl in southwestern Ghana and southeastern Côte d'Ivoire is isolated from most of the species' known populations in the west.
Unexpectedly the projected impacts of climate change on the geographic distribution of White-breasted Guineafowl were minimal, suggesting stability across the species' range for the present and in the future, at least as regards climate change effects. Low sensitivity to climate change in this species does match the general observation for West African birds (Carr et al. 2014; Baker et al. 2015). However, although minimum, the notable projected coastal range loss of the species should be considered in any future conservation planning. This potential range loss could be attributed to increasing projected global sea level rise that would increase the chances of coastal erosion, thereby changing microclimatic conditions. Liberia is already experiencing rapid coastal erosion due 


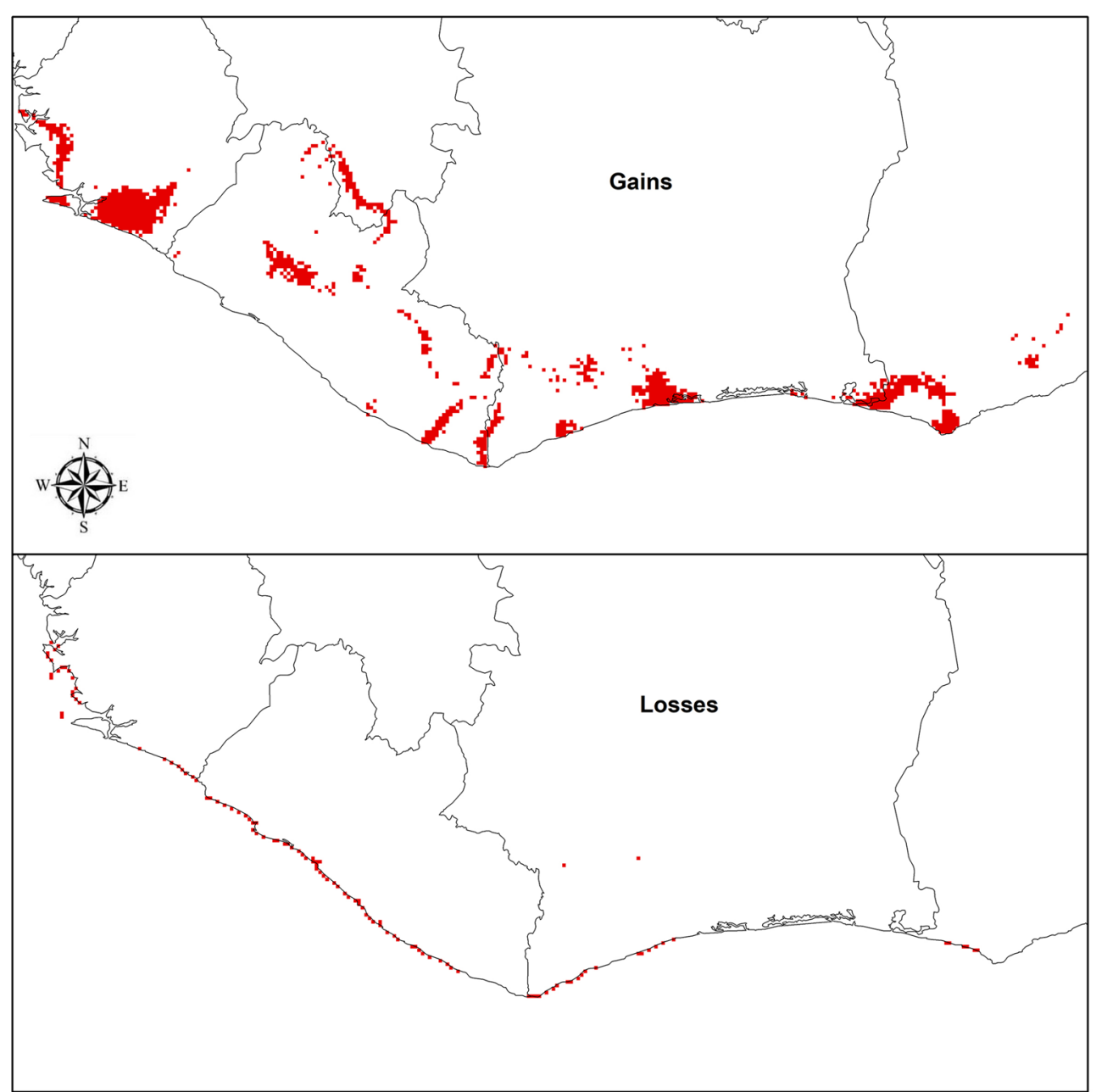

Fig. 4 Climatic range gains and losses for White-breasted Guineafowl projected based on climate model projections for 2050. The top map shows potential range gains while the bottom map shows potential range losses

to global sea level rise. Galliformes are thought to be at most risk from climate induced changes in higher elevations ( $\mathrm{Li}$ et al. 2010); the low elevation habitat in West Africa inhabited by White-breasted Guienafowl will not face such extreme climate shifts. However, an important caveat is that the potential behavioral and demographic impacts of climate change on West African birds remain largely unexplored. For example, the cues for the timing of breeding for Black Grouse (Tetrao tetrix) in Finland have been shifted, such that the survival probability of chicks is much lower, as they are exposed to lower temperatures as the breeding cues shift further into the summer (Ludwig et al. 2006). These demographic consequences of climate change need to be investigated fully for the White-breasted Guineafowl and other West African taxa.

A prominent observation in our results, however, was the projected westwards potential climate-change-driven range expansion of the species, extending to the Western Peninsula National Park in southwestern Sierra Leone. We know of no record of the species from this site, but it already offers suitable forested habitat for some of the Upper Guinea Forest endemics (e.g. White-necked Picathartes Picathartes gymnocephalus). However, given the projected potential connectivity between Western Peninsula National Park and GRNP, under favorable climatic conditions in the future, this forest complex could exemplify a classic metapopulational dynamics, with GRNP providing viable source populations of White-breasted Guineafowl to colonize the site.

\section{Conclusions}

In conclusion, we show that White-breasted Guineafowl has a broader present-day distribution than represented by IUCN (2018), and that projected climate-changedriven impacts on the species are minimal. This latter 
result suggests that forest cover, and not necessarily climate change, is the most important driver of the species' geographic distribution. As such, national and regional conservation efforts should prioritize forest protection and anthropogenic threats (e.g. hunting pressure, shifting cultivation) impacting the species. This new perspective on the species' distribution is important for its conservation given increasing threats across its range. It provides an opportunity to include isolated populations that were originally overlooked for lack of information. These results demonstrate that by combining remotely sensed data and climatic data in ecological niche modeling, we understand not only species' responses to global climate, but also their responses to land use and land cover.

\section{Additional files}

Additional file 1: Table S1. General circulation models and the two emissions scenarios used in our models. Table S2. Metrics of final best models selected from the calibration of climatic and MODIS data.

Additional file 2. Climatic data model calibration output using kuenm R Package.

\section{Acknowledgements}

We are thankful to A. Townsend Peterson for his helpful review and comments during the preparation of this manuscript and to members of the KUENM group at the University of Kansas for their useful feedback on methods used in this study.

\section{Authors' contributions}

$\mathrm{BF}$ and $\mathrm{MG}$ conceived of the project ideas and planned the study. BB collected data. BF and DJG conducted research and data analysis. BF, MG, BB, and DJG composed manuscript. All authors read and approved the final manuscript.

\section{Funding}

This project was supported by Conservation International through a Global Environment Facility-funded Grant No. GEF-5810.

\section{Availability of data and materials}

The data analyzed during the current study are available in the following databases: the Global Biodiversity Information Facility (GBIF; https://www.gbif. org). Data from surveys in Sapo National Park in Liberia and Gola Rainforest National Park in Sierra Leone are available from the corresponding author on reasonable request. Environmental datasets are available at https:/terra.nasa. gov/data and http://www.worldclim.org.

\section{Ethics approval and consent to participate}

Not applicable.

\section{Consent for publication}

Not applicable.

\section{Competing interests}

The authors declare that they have no competing interests.

\section{Author details}

${ }^{1}$ Biodiversity Institute, University of Kansas, Lawrence, KS 66045, USA. ${ }^{2}$ Centro de Agroecoloía y Ambiente, Instituto de Ciencias, Benemérita Universidad Autónoma de Puebla, Puebla, Puebla, Mexico. ${ }^{3}$ Royal Society for the Protection of Birds, Gola Rainforest National Park, Kailahun, Sierra Leone. ${ }^{4}$ School of Natural and Environmental Sciences, Newcastle University, Newcastle upon Tyne NE1 7RU, UK.
Received: 17 December 2018 Accepted: 27 May 2019

Published online: 10 June 2019

\section{References}

Allport G. The status and conservation of threatened birds in the Upper Guinea forest. Bird Conserv Int. 1991;1:53-74.

Baker DJ, Hartley AJ, Burgess ND, Butchart SHM, Carr JA, Smith RJ, Belle E, Willis SG. Assessing climate change impacts for vertebrate fauna across the West African protected area network using regionally appropriate climate projections. Divers Distrib. 2015;21:991-1003.

Barve N, Barve V, Jiménez-Valverde A, Lira-Noriega A, Maher SP, Peterson AT, Soberón J, Villalobos F. The crucial role of the accessible area in ecological niche modeling and species distribution modeling. Ecol Model. 2011;222:1810-9.

Brown JL. SDMtoolbox: a python-based GIS toolkit for landscape genetic, biogeographic and species distribution model analyses. Methods Ecol Evol. 2014;5:694-700.

Campbell LP, Luther C, Moo-Llanes D, Ramsey JM, Danis-Lozano R, Peterson AT. Climate change influences on global distributions of dengue and chikungunya virus vectors. Philos Trans R Soc B. 2015;370:20140135.

Carr JA, Hughes AF, Foden WB. A climate change vulnerability assessment of West African species. Cambridge: Technical Report, UN Environment World Conservation Monitoring Centre; 2014.

Chapman AD. Principles of data cleaning-primary species and species occurrene data, version 1.0. Copenhagen: Report for the Global Biodiversity Information Facility. http://www.gbif.org/resource/80528 (2005).

Cobos ME, Peterson AT, Barve N, Osorio-Olvera L. kuenm: an R package for detailed development of ecological niche models using Maxent. PeerJ. 2019;7:e6281.

Davies AG. The Gola forest reserves, Sierra Leone. Wildlife conservation and forest management. Gland: International Union for Conservation of Nature and Natural Resources; 1987.

Díaz S, Pascual U, Stenseke M, Martín-López B, Watson RT, Molnár Z, Hill R, Chan KMA, Baste IA, Brauman KA, et al. Assessing nature's contributions to people. Science. 2018;359:270-2.

Didan K, Munoz AB, Solano R, Huete A. MODIS vegetation index user's guide (MOD13series). Vegetation Index and Phenology Lab, The University of Arizona; 2015. p. 1-38.

Dowsett-Lemaire F, Dowsett RJ. The avifauna of the proposed Kyabobo National Park in eastern Ghana. Malimbus. 2007;29:61-88.

Eastman JR. Accessed in TerrSet version, 18.07. Worcester: Clark Labs, Clark University; 2015

ESRI. ArcGIS Release 10.5.1. Redlands: Environmental Systems Research Institute; 2017.

Francis IS, Penford N, Gartshore ME, Jaramillo A. The White-breasted Guineafowl Agelastes meleagrides in Taï National Park, Côte d'Ivoire. Bird Conserv Int. 1992;2:25-60.

Freeman B, Roehrdanz PR, Peterson AT. Modeling endangered mammal species distributions and forest connectivity across the humid Upper Guinea lowland rainforest of West Africa. Biodivers Conserv. 2019a;28:671-85.

Freeman B, Danjuma DF, Molokwu-Odozi M. Status of globally threatened birds of Sapo National Park, Liberia. Ostrich. 2019b;90:19-24.

Fuller RA, Garson PJ. Pheasants: status survey and conservation action plan 2000-2004. UK: IUCN; 2000.

GBIF (Global Biodiversity Information Facility Database). GBIF occurrence download. https://doi.org/10.15468/dl.jdkowf (2017). Accessed 28 Nov 2017.

Gocic M, Trajkovic S. Spatiotemporal characteristics of drought in Serbia. J Hydrol. 2014;510:110-23.

Guisan A, Tingley R, Baumgartner JB, Naujokaitis-Lewis I, Sutcliffe PR, Tulloch AIT, Regan TJ, Brotons L, McDonald-Madden E, Mantyka-Pringle C, et al. Predicting species distributions for conservation decisions. Ecol Lett. 2013;16:1424-35.

Hijmans RJ, Cameron SE, Parra JL, Jones PG, Jarvis A. Very high resolution interpolated climate surfaces for global land areas. Int J Climatol. 2005:25:1965-78.

Huete A, Justice C, Van Leeuwen W. MODIS vegetation index (MOD13). Algorithm Theor Basis Doc. 1999;3:213. 
Hurvich CM, Tsai C-L. Regression and time series model selection in small samples. Biometrika. 1989;76:297-307.

IPBES. Assessment report on biodiversity and ecosystem services for Africa. Intergovernmental Science-Policy Platform on Biodiversity and Ecosystem Services. https://www.ipbes.net/assessment-reports/africa (2018).

IUCN. The IUCN red list of threatened species. http://www.iucnredlist.org (2018).

Janes T, Hartley A. Regional climate projections for West Africa. Cambridge: Technical Report, UN Environment World Conservation Monitoring Centre; 2010

Klop E, Lindsell JA, Siaka AM. The birds of Gola Forest and Tiwai Island, Sierra Leone. Malimbus. 2010:32:33-58.

Li R, Tian H, Li X. Climate change induced range shifts of Galliformes in China. Integr Zool. 2010:5:154-63.

Ludwig GX, Alatalo RV, Helle P, Lindén H, Lindström J, Siitari H. Short-and longterm population dynamical consequences of asymmetric climate change in black grouse. Phil Trans R Soc B. 2006;273:2009-16.

Malcolm JR, Liu C, Neilson RP, Hansen L, Hannah LEE. Global warming and extinctions of endemic species from biodiversity hotspots. Conserv Biol. 2006:20:538-48.

Manjunath Aradhya VN, Niranjan SK, Hemantha Kumar G. Probabilistic neural network based approach for handwritten character recognition. Int J Comput Commun. 2010;1:9-13.

Martins DS, Raziei T, Paulo AA, Pereira LS. Spatial and temporal variability of precipitation and drought in Portugal. Nat Hazard Earth Syst. 2012;12:1493-501.

Mittermeier RA, Myers N, Thomsen JB, Da Fonseca GA, Olivieri S. Biodiversity hotspots and major tropical wilderness areas: approaches to setting conservation priorities. Conserv Biol. 1998;12:516-20.

MODIS Database. https://modis.gsfc.nasa.gov/data. Accessed 25 Sept 2017.

Myers N, Mittermeier RA, Mittermeier CG, da Fonseca GAB, Kent J. Biodiversity hotspots for conservation priorities. Nature. 2000;403:853-8.

Olson DM, Dinerstein E. The Global 200: priority ecoregions for global conservation. Ann Mo Bot Gard. 2002;89:199-224.

Pearson RG, Dawson TP. Predicting the impacts of climate change on the distribution of species: are bioclimate envelope models useful? Glob Ecol Biogeogr. 2003;12:361-71.

Pearson RG, Raxworthy CJ, Nakamura M, Townsend Peterson A. Predicting species distributions from small numbers of occurrence records: a test case using cryptic geckos in Madagascar. J Biogeogr. 2007;34:102-17.
Peterson AT, Papeş M, Soberón J. Rethinking receiver operating characteristic analysis applications in ecological niche modeling. Ecol Model. 2008:213:63-72.

Peterson AT, Soberón J, Pearson RG, Anderson RP, Martínez-Meyer E, Nakamura M, Araújo MB. Ecological niches and geographic distributions. Princeton: Princeton University Press; 2011.

Phillips SJ, Dudík M, Schapire RE. A maximum entropy approach to species distribution modeling. In: Proceedings of the twenty-first international conference on Machine learning Association for Computing Machinery; 2006. p. 83.

Şekercioğlu ÇH, Primack RB, Wormworth J. The effects of climate change on tropical birds. Biol Conserv. 2012;148:1-18.

Shcheglovitova M, Anderson RP. Estimating optimal complexity for ecological niche models: a jackknife approach for species with small sample sizes. Ecol Model. 2013;269:9-17.

Sobrino JA, Julien Y. Time series corrections and analyses in thermal remote sensing. Thermal infrared remote sensing. Dordrecht: Springer; 2013. p. 267-85.

Stattersfield A, Crosby M, Long A, Wege D. Endemic bird areas of the world: priorities for biodiversity conservation. Cambridge: BirdLife International; 1998.

Stephens PA, Mason LR, Green RE, Gregory RD, Sauer JR, Alison J, Aunins A, Brotons L, Butchart SHM, Campedelli T, et al. Consistent response of bird populations to climate change on two continents. Science. 2016:352:84-7.

Waltert M, Seifert C, Radl G, Hoppe-Dominik B. Population size and habitat of the White-breasted Guineafowl Agelastes meleagrides in the Taï region, Côte d'Ivoire. Bird Conserv Int. 2010;20:74-83.

WPA-IUCN. Guidelines for the re-introduction of Galliformes for conservation purposes. Gland: World Pheasant Association and International Union for Conservation of Nature; 2009.

Zhang JP, Zhu T, Zhang QH, Li CC, Shu HL, Ying Y, Dai ZP, Wang X, Liu XY, Liang $A M$, Shen $H X$, Yi BQ. The impact of circulation patterns on regional transport pathways and air quality over Beijing and its surroundings. Atmos Chem Phys. 2012;12:5031-53.

Ready to submit your research? Choose BMC and benefit from:

- fast, convenient online submission

- thorough peer review by experienced researchers in your field

- rapid publication on acceptance

- support for research data, including large and complex data types

- gold Open Access which fosters wider collaboration and increased citations

- maximum visibility for your research: over $100 \mathrm{M}$ website views per year

At BMC, research is always in progress.

Learn more biomedcentral.com/submissions 